\title{
Pancreatic Non-Hodgkin Lymphoma
}

National Cancer Institute

\section{Source}

National Cancer Institute. Pancreatic Non-Hodgkin Lymphoma. NCI Thesaurus. Code C5789.

A non-Hodgkin lymphoma that arises from the pancreas with the bulk of the tumor localized to this organ. The vast majority of cases are of B-cell phenotype and include mucosa-associated lymphoid tissue lymphomas, follicular lymphomas, and diffuse large B-cell lymphomas. 